\title{
Ensaio
}

\section{Natureza e Cultura: Sentidos da diversidade}

Felipe Süssekind*

\section{Resumo}

É bem conhecido o fato de que a antropologia, em suas vertentes clássicas, se caracteriza por estabelecer uma grande divisão entre natureza e cultura, a qual inclui a demarcação de diversas oposições complementares: corpo e alma, ambiente e civilização, fato e valor, animal e humano, entre outras. 0 ponto de partida para a discussão aqui proposta é refletir sobre esse grande divisor, investigando alguns dos limites e desdobramentos dos conceitos de "cultura" e de "natureza" no campo da antropologia contemporânea. 0 objetivo é mostrar como esse par conceitual tem sido sistematicamente colocado à prova tanto a partir do contato com a alteridade radical do pensamento de povos não ocidentais quanto nos chamados estudos da ciência e da tecnologia, que ao longo das últimas décadas se desdobraram em abordagens inovadoras da política, da economia, ou seja, das grandes instituições da modernidade ocidental. Em relação ao conceito de cultura, objeto por definição da própria disciplina antropológica, a referência aqui é principalmente a sua retomada crítica a partir dos anos 1970. No que se refere ao seu par, o conceito de natureza, evoco uma problemática mais recente, em que o que se coloca em questão é a ideia mesma da natureza como uma unidade exterior e transcendente, um domínio independente do humano. A questão se desdobra em duas: (1) uma reflexão sobre as relações entre humanos e animais, problematizando a atribuição prematura do campo da moral a uma dimensão estritamente humana, e (2) um questionamento do papel da natureza nas ciências, em diálogo com saberes indígenas ou tradicionais.

\section{Palavras-chave}

Natureza. Cultura. Diversidade. Cosmologia. Animal.

\section{Abstract}

It is well known that anthropology, in its classic strands, is characterized for establishing

\footnotetext{
* Felipe Süssekind é Doutor em Antropologia pelo Museu Nacional (MN) da Universidade Federal do Rio de Janeiro (UFRJ); e professor do Departamento de Ciências Sociais da Pontifícia Universidade Católica do Rio de Janeiro (PUC-Rio). E-mail: felipesussekind@puc-rio.br.
} 
a great division between nature and culture, which includes the demarcation of several complementary oppositions: body and soul, environment and civilization, fact and value, animal and human, among others. The starting point for the discussion proposed here is to reflect about this great divider, investigating a few of the limits and unfolding of the concepts of "culture" and "nature" in the contemporary anthropology field. The goal is to show how this conceptual pair has been systematically put to the proof starting from the contact with the radical otherness of non-Western people thinking, as well as in the so-called studies of science and technology which, throughout the last decades, have unfolded in innovative approaches regarding politics and economy, which are the great institutions of Western modernity. Regarding the concept of culture, an object by definition of the anthropology subject, the reference here is mainly its critical retake started in the 1970s. Regarding its pair, the concept of nature, I evoke a recent problematic, where what is in question is the idea of this same nature as an exterior and transcendent unity, an domain that does not depend on humans. The questions turn into two: (1) a reflection regarding the relationship between humans and animals, problematizing the premature attribution of the moral field to a strictly human dimension, and (2) questioning nature's role in science, dialoguing with traditional or indigenous knowledge.

\section{Keywords}

Nature. Culture. Diversity. Cosmology. Animal.

\section{Grandes divisores}

Entre os anos 1980 e 1990, uma série de debates realizados em Manchester abordaram temas-chave para a antropologia contemporânea, reunindo antropólogos de diversas áreas. Esses debates deram origem ao livro Key debates in Anthropology, editado por Tim Ingold, publicado em 1996. A cada ano, os debates de Manchester eram organizados em torno de uma moção, que deveria ser defendida por dois antropólogos e refutada por outros dois, antes de ser discutida por todos os participantes.

O tema do ano de 1989 foi o conceito de sociedade, em suas relações intrínsecas com termos como o indivíduo, a comunidade, a nação e o Estado. A moção apresentada afirmava que "O conceito de sociedade está teoricamente obsoleto", ideia defendida, neste caso, por Marilyn Strathern e Christina Toren. A discussão girava em torno dos limites colocados pela tradição antropológica ao definir a sociedade como uma totalidade 
circunscrita complementada numa relação parte-todo pela noção de indivíduo. Para Strathern, o conceito de sociedade teria se fechado em uma caixa-preta, sendo esvaziado de seu potencial teórico e reificado como um objeto predeterminado, sendo necessário para a antropologia a busca de um vocabulário alternativo para dar conta dos processos de socialização, constituição de relações e formação de grupos, estudados pelos antropólogos ${ }^{1}$.

A moção no ano seguinte, 1990, por sua vez, foi “ Os mundos humanos são construídos culturalmente". O debate em torno dela colocava em questão as formas de determinismo biológico e cultural, abordando as fronteiras entre as ciências humanas e as ciências da natureza, ou antropologia e biologia. Os temas discutidos, neste caso, incluíam a oposição entre natureza e cultura, a concepção de organismo e de sujeito social, a determinação dos limites do humano pela genética e pela cultura, e as relações entre humanos e animais. A discussão levava em consideração as divisões disciplinares e a inclusão e exclusão de temas associados à ecologia e às ciências biológicas no campo da antropologia social.

Os Key debates foram publicados há quase trinta anos e representam, a meu ver, um bom guia de temas centrais para antropologia contemporânea. Cito essas duas moções com o objetivo de chamar atenção para o tema que pretendo abordar, que é o da oposição entre natureza e cultura.

Essa grande oposição tem sido colocada em xeque de diversas formas, em consonância com o diagnóstico de um esgotamento do repertório moderno que remete ao feminismo, à crise ecológica, e às diversas formas de resistência ao colonialismo. Para elaborar uma reflexão sobre os limites da oposição entre natureza e cultura, minha intenção neste artigo é investigar alguns dos sentidos que essas categorias adquirem na história do pensamento antropológico, para, em seguida, apresentar proposições que apontam para o seu esgotamento conceitual. Nesse sentido, vou abordar de forma sucinta duas problemática até certo ponto complementares: as relações entre humanos e animais e aquelas entre modos de conhecimento

\footnotetext{
${ }^{1} \mathrm{O}$ texto de Strathern se tornaria um dos capítulos do livro O efeito etnográfico, publicado no Brasil em 2014. Em outros capítulos, em particular "Sem natureza, sem cultura: o caso Hagen" e "Dando apenas uma força à natureza? A cessão temporária de Útero: um debate sobre tecnologia e sociedade", Strathern desenvolve uma reflexão robusta sobre o par natureza-cultura, tendo como referência o contraste entre as concepções ocidentais e aquelas da Melanésia.
} 
tradicionais (ou indígenas) e científicos. As duas discussões envolvem uma convergência possível entre a etnologia e a antropologia da ciência ${ }^{2}$ no sentido do questionamento do par natureza-cultura como um constructo conceitual e político definido em termos de unidade e multiplicidade.

Como enfatizou Tim Ingold em um artigo bastante conhecido no Brasil, o objeto das ciências naturais e da biologia é a espécie humana, enquanto o objeto da filosofia e das ciências humanas e sociais é a condição humana (INGOLD, 1995). Os problemas históricos da sobreposição entre os dois sentidos da humanidade mostram o quanto cada um dos campos é informado necessariamente pelo outro. Por um lado, o "animal" surge como não humano genérico (natural, mecânico) no caso das ciências humanas e da antropologia, enquanto, de outro lado, o "humano" aparece como não animal genérico (artificial, cultural) no caso da biologia e das ciências naturais. Ambas definições pela falta, ou em negativo, criando em cada caso espelho invertido daquilo que não é o objeto de interesse da disciplina em questão ${ }^{3}$.

A definição dos viventes como sujeitos (humanos) e objetos (não humanos) remete à cisão estabelecida pelo pensamento moderno entre ciências humanas e ciências da natureza. A demarcação de fronteiras disciplinares remete, por sua vez, ao contraste o campo dos fatos e o campo dos valores, ou o campo da instrumentalidade e o da intencionalidade. Nesse sentido, o interesse pela natureza, pelos ecossistemas, animais ou temas correlatos tendeu historicamente a se restringir às áreas de interesse da biologia e da antropologia física, enquanto o campo da cultura, das representações e da moral tendeu a se restringir aos sujeitos e coletivos humanos estudados pela antropologia social ou cultural em suas várias vertentes. Ingold defende que há um modelo de base sustentando essa divisão de tarefas entre as disciplinas, o qual se refere a um duplo movimento: a oposição entre a natureza e cultura é seguida pelo contraste entre o moderno e o tradicional, sendo este último par tratado em termos de

\footnotetext{
${ }^{2}$ Refiro-me, neste caso, basicamente à literatura proveniente dos chamados estudos da ciência e da tecnologia, chamados em inglês de Science Studies ou STS (Science and Technology Studies ou ainda Science, Technology and Society).

${ }^{3}$ A discussão de Ingold se volta criticamente para o fato de que a condição humana, ou condição de pessoa, é necessariamente vinculada, na cosmovisão ocidental, ao pertencimento à espécie natural Homo Sapiens.
} 
sistemas de valores e o primeiro em termos de sistemas de fatos (INGOLD, 2000).

Nesse sentido, e no que se refere às ideias canonizadas pela antropologia ao longo do tempo, a ordem da natureza pode ser definida como uma espécie de suporte material para os projetos, universos conceituais e organizações sociais humanos. Em todo caso, trata-se de uma categoria que estabelece um limite daquilo que é objeto próprio da antropologia. $\mathrm{O}$ conceito de cultura, por outro lado, como sabemos, faz parte da definição mesma deste objeto, alternando-se no papel de protagonista da disciplina com o conceito de sociedade ${ }^{4}$.

\section{Cultura}

Estabilizado pelo discurso antropológico, definido em termos de totalidades integradas no espaço e contínuas no tempo, o conceito antropológico de cultura tem sido amplamente questionado e revisto desde que foi formulado como objeto da antropologia ${ }^{5}$. Nos anos 1970, a antropologia interpretativa de Clifford Geertz se aproximou da teoria literária e da hermenêutica para colocar em questão a escrita etnográfica e as possibilidades de representação dos outros povos na antropologia. A distinção entre cultura e razão prática, proposta por Marshall Sahlins (1976), era uma crítica forte das concepções utilitaristas e pragmáticas da cultura, contrapondo-as àquelas que concebem a ordem cultural a partir dos esquemas significativos ou simbólicos desde os quais o mundo é vivido.

Conferindo ao pensamento indígena um estatuto epistemológico equivalente ao do pensamento ocidental, Lévi Strauss (1962) havia produzido uma síntese particular da relação entre a ordem do significado e a das organizações sociais. Retomando o estruturalismo levistraussiano em outras bases, Sahlins investigou ainda o modo como as sociedades não ocidentais interpretam os processos de colonização e de contato cultural em seus próprios termos (SAHLINS, 1985). Com isso, sua obra aponta para

\footnotetext{
${ }^{4}$ Não discuto no presente artigo o conceito de sociedade. Uma discussão sobre a sua obsolescência encontra-se em Strathern (2014a).

${ }^{5}$ A definição do conceito de "cultura" por Edward Tylor, em 1871, estabelece um marco temporal canônico para a disciplina.
} 
uma espécie de descolonização epistemológica em relação aos discursos hegemônicos do Ocidente, em particular o discurso histórico.

Pierre Clastres, quando define os termos de sua antropologia política, ainda nos anos 1970, afirma que uma antropologia renovada precisaria ser capaz de estabelecer um diálogo com apenas dois interlocutores - um diálogo que não teria o pressuposto (que vem da filosofia grega, do modelo platônico), de um terceiro termo, externo e transcendente - ou de um ponto de vista global, ou neutro (CLASTRES, 1974). Partindo da percepção de que a razão ocidental se constitui sempre excluindo alguma coisa, através de categorias da alteridade como a do "selvagem" ou do "primitivo", Clastres chamava atenção para a posição de transcendência contida no discurso antropológico.

Em A invenção da Cultura, obra publicada em 1975 que, entretanto, só seria incorporada ao debate acadêmico mais amplo muito mais tarde, Roy Wagner propôs uma definição estritamente antropológica da noção de cultura, entendendo-a como um dispositivo acionado no encontro entre diferentes experiências, povos ou pessoas. A cultura, nesse sentido, é aquilo que é colocado em ação tanto no trabalho de campo do antropólogo quanto no encontro entre diferentes sociedades. Trata-se de um dispositivo que pressupõe um duplo movimento, ou o que Wagner chamou de uma "invenção" e uma "contra-invenção". O antropólogo precisa de alguma forma "inventar" uma cultura para aqueles que estuda, isto é, produzir, por meio de uma atividade criativa, uma descrição do que seria a vida do grupo ao qual se vinculou na experiência etnográfica. Obviamente, essa experiência tem relação com alguma coisa que "está lá", com o modo de vida daqueles que o antropólogo está descrevendo, mas é evidente também que ele só é capaz de fazer isso a partir de seu ponto de vista particular, do ponto de vista situado e localizado de sua própria cultura (WAGNER, 2010, p.28).

Além disso, quando se entra em contato com outros povos, como todos sabemos, experimentamos de um modo novo e diferente aquilo que é o lugar de onde viemos; ou seja, percebemos, no contato com o diferente, quais são os elementos específicos de nossa própria experiência, os modos de comportamento e as visões de mundo que antes tomávamos como naturais. Nesse sentido, diante da alteridade nós necessariamente "contrainventamos" - e essa é também uma experiência criativa - uma cultura para nós mesmos. Wagner tira todas as consequências dessa ideia ao defender, jogando com a ideia pós-colonial no pensamento antropológico de que 
somos todos ("nós" e "eles") nativos (ou seja, vivemos em culturas), a ideia de que somos todos antropólogos (i. é, inventores da cultura).

O dispositivo antropológico, no sentido wagneriano, deriva de uma definição mútua, uma experiência que ele chamou de uma antropologia reversa (2010, p.67). A dupla invenção por parte de um eu corresponde a uma dupla invenção por parte um outro. A questão importante, nesse caso, é que o que conta como cultura para um povo não é a mesma coisa que conta como cultura para outro povo. O que interessava aos Daribi, povo da Nova Guiné que Roy Wagner estudou, quando definiam em sua contraantropologia a "cultura" dos ocidentais, era muito diferente daquilo que consideraríamos próprio do domínio da cultura.

Mas, isso não é tudo. O multiculturalismo que caracteriza a atitude da antropologia pós-colonial, ou seja, o argumento da diversidade cultural, sempre esteve fundado em sua contraparte, a saber, a ideia de uma natureza única, objetiva. As noções de cultura e sociedade, além de circunscreverem o objeto das ciências sociais, também definem, por exclusão, aquilo que não faria parte do escopo de interesses delas, a saber: a natureza, a ordem dos fatos objetivos.

\section{Natureza}

Vivemos em uma cultura, assim como os outros, porém sempre consideramos que a nossa cultura - justamente ao separar a natureza da cultura - produz um acesso privilegiado ao mundo, às coisas, por meio do pensamento científico. Roy Wagner chamou a isso de um jogo de dois contra um: os outros teriam apenas cultura, e nós teríamos natureza e cultura. A universalidade da natureza seria, nesse sentido, o argumento que permitira aos ocidentais reduzirem as outras culturas a sistemas de representações ou de crenças, enquanto concebiam a sua própria cultura em termos objetivos e universais. A esse respeito, Wagner afirma:

Se insistirmos em objetificar outras culturas por meio da nossa realidade, transformamos as objetificações delas da realidade em uma ilusão subjetiva, um mundo de "meros símbolos", outras classificações daquilo que "realmente está lá". Assim, a criatividade da invenção da realidade dessas culturas é subvertida em termos da nossa própria criatividade, transformando a coisa que aprendemos como a cultura deles em uma metáfora estranha e acidental da racionalidade (2010, p.219). 
O autor chama atenção, neste caso, para o papel da antropologia como uma espécie de Grande Inquisidor epistemológico, que nos torna incapazes de ver algo além da nossa própria história, de uma história em que não há uma alteridade significativa.

Partindo de uma problemática diferente, associada à filosofia da ciência, Bruno Latour usa argumentos análogos quando se refere ao papel da concepção da natureza na expansão e a dominação promovida pelo Ocidente diante dos outros povos do mundo:

Para compreender a profundidade desta Grande Divisão entre Eles e Nós, é preciso retornar a esta outra Grande Divisão entre os humanos e os não-humanos (...). De fato, a primeira é a exportação da segunda. Nós, ocidentais, não podemos ser apenas mais uma cultura entre outras porque mobilizamos também a natureza. Não mais, como fazem as outras sociedades, uma imagem ou representação simbólica da natureza, mas a natureza como ela é, ou ao menos tal como as ciências a conhecem, ciências que permanecem na retaguarda, impossíveis de serem estudadas, jamais estudadas. No centro da questão do relativismo encontrase, portanto, a questão da ciência." (2005, p.96-97).

De acordo com Latour, ao acusarem os "primitivos" de fetichistas (que acreditam em entidades que eles próprios fabricaram), os modernos acreditam na universalidade de sua própria cultura, e encobrem o fetichismo inerente às suas próprias práticas. A antropologia simétrica proposta por ele teve como finalidade justamente libertar a antropologia do paradoxo de se constituir como uma ciência da não ciência. O ponto de partida é a ideia de que o discurso antropológico precisa se tornar capaz de mobilizar a natureza, e não apenas da cultura, para que a experiência etnográfica não fique no plano da representação. É nesse sentido que Latour questiona a oposição e propõe uma antropologia comparada capaz de colocar lado a lado o que chama de "naturezas-culturas" (2005, p.12).

O que a experiência antropológica mostra, em todo caso, é que não há como se estudar outra cultura sem que o próprio conceito de cultura esteja em jogo. E o mesmo se dá em relação seu par conceitual. A natureza como algo exterior e transcendente, apartada do humano, é o que torna possível o desenvolvimento das ciências, assim como a demarcação de uma separação absoluta entre o Ocidente moderno e o resto do mundo. Essas duas grandes divisões fazem parte da concepção que origina um determinado tipo de história, fundada na ideia de progresso. 
No que se refere ao conceito de cultura, as indicações que apresentei acima nos oferecem um embasamento para investigar os modos de conhecer colocado em jogo na experiência etnográfica. O contraste entre as práticas de conhecimento da antropologia e aquelas dos povos que ela estuda levaram, ao mesmo tempo, a uma radicalização do questionamento acerca dos sentidos do conceito ocidental da natureza, seja como um princípio universal seja como algo que se contrapõe ao campo da cultura.

A divisão entre natureza e cultura e a demarcação de fronteiras entre humanos e não humanos, como vimos, têm sido recorrentemente colocadas em questão no pensamento antropológico contemporâneo. Essas grandes divisões são tematizadas atualmente por antropólogos que têm buscado a revalorização político-metafísica de um pensamento que pode ser classificado como "animista" ou "panpsiquista", entre eles autores como Eduardo Viveiros de Castro, Phillipe Descola e Tim Ingold. Tendo como ponto de partida as cosmologias indígenas da Amazônia, Descola (2005) recuperou o termo "animismo" para designar uma ontologia particular que contrasta o "naturalismo" ocidental com outras ontologias possíveis 6 .

$\mathrm{O}$ fato de que existem povos que não concebem a natureza como um domínio exterior e manejável, disponível para os humanos, oferece imagens de outras relações possíveis com os seres não humanos com os quais compartilhamos a nossa existência. Não se trata aqui de idealizar o outro, o exótico, mas sim de reconhecer que, ao estudar outras culturas, a antropologia apresenta outros mundos possíveis a partir dos quais poderíamos repensar os nossos modelos e valores, assim como, talvez, as dimensões da crise ambiental e civilizatória em que nos encontramos.

Os conceitos de perspectivismo e de mutinaturalismo, elaborados por Viveiros de Castro (2002) a partir do pensamento ameríndio, colocam também potencialmente em xeque alguns pressupostos fundamentais do pensamento dicotômico moderno. São conceitos que descrevem o modo como os povos amazônicos concebem o mundo em termos de múltiplos pontos de vista que não se reúnem em uma totalidade exterior e unificada. Enquanto o pensamento ocidental postularia a existência de uma só natureza e várias culturas, o pensamento indígena fala em uma só cultura e naturezas particulares dependendo do ponto de vista do observador (VIVEIROS DE CASTRO, 2002).

" $\mathrm{O}$ "totemismo" e o "analogismo" completam o sistema de quatro ontologias proposto por Descola (2005). 
No âmbito da antropologia da ciência, por outro lado, autores como Bruno Latour, Michel Callon, John Law, Isabelle Stengers e Donna Haraway, entre outros, propuseram nas últimas décadas uma potente revisão crítica dos preceitos modernos e dos métodos analítico-descritivos das ciências, fundados tradicionalmente no realismo e na autoridade científica. Surgiram, nesse processo, novos conceitos que implicam uma dissolução efetiva das fronteiras entre humanos e não humanos (LATOUR, 2005; HARAWAY, 1985).

\section{Os sentidos do animal na antropologia}

Nos últimos trinta anos, aproximadamente, como vimos, tanto as discussões antropológicas sobre coletivos indígenas quanto aquelas voltadas para os campos da ciência e da técnica têm revelado ligações cada vez mais intrincadas entre humanos e não humanos. Os sentidos do animal, seu estatuto e lugar passaram, desde então, a ser revistos nos debates teóricos da antropologia a partir de um questionamento amplo sobre a separação moderna entre os domínios da natureza e da cultura, ou do sujeito e do objeto. A formulação ocidental do humano como medida de todas as coisas é complementar à consolidação da concepção da natureza como recurso, e dos seres não humanos como instrumentos ou objetos para os projetos humanos. Na filosofia moderna, e em particular na tradição cartesiana, como se sabe, o animal designa a condição oposta à condição humana, ou seja, designa a negação ou ausência daquilo que se convenciona como sendo a singularidade humana: razão ou inteligência, sentimento, consciência de si e da morte, linguagem, sentimento moral, entre outros atributos.

De acordo com Jacques Derrida, a noção de animal (no singular genérico) é contraproduzida pela ideia de humanidade no pensamento moderno, remetendo sempre a uma ausência ou falta daquilo que caracteriza o humano: razão, linguagem, etc. É a partir dessa constatação que o filósofo propõe, para descrever o modo como a humanidade tem pensado o animal, o conceito de "Animot", como uma quimera que espera para ser morta. A partícula "mot" ("palavra", "nome") refere-se neste caso ao ato de nomear como um ato de separar o humano do animal (DERRIDA, 2002).

Partindo de uma reflexão análoga, Giorgio Agamben se refere ao aparato ou dispositivo conceitual que mantém a humanidade suspensa entre o terrestre e o celeste, corpo e alma, na tradição católica, ou entre humano e animal, civilização e natureza, na classificação científica. A emancipação da 
natureza envolve uma constante demarcação de limites entre o humano e o não humano, uma máquina de reprodução desses limites, uma máquina cujo funcionamento foi descrito por Agamben em termos de uma "máquina antropológica": aquela que qualifica determinado vivente como "humano" - sujeito de direitos - desqualificando outro como "animal" - objeto ou instrumento (AGAMBEN, 2004).

Trata-se de um dispositivo que produz ao mesmo tempo o não humano e o sub-humano, o "animal" e o "escravo", algo que se aproxima do que afirma Lévi-Strauss em seu célebre ensaio sobre Rousseau:

\begin{abstract}
"Nunca antes do termo desses últimos quatro séculos de sua história, o homem ocidental percebeu tão bem que, ao arrogar-se o direito de separar radicalmente a humanidade da animalidade, concedendo a uma tudo o que tirava da outra, abria um ciclo maldito. E que a mesma fronteira, constantemente empurrada, serviria para separar homens de outros homens, e reivindicar em prol de minorias cada vez mais restritas o privilégio de um humanismo corrompido de nascença por ter feito do amorpróprio seu princípio e noção". (LÉVI-STRAUSS, 2013, p.53).
\end{abstract}

A distinção entre natureza e cultura, em suma, é o operador que permite que nós classifiquemos os seres humanos como sujeitos portadores de direitos intrínsecos e os seres não humanos como objetos naturais ou artificiais que possuem apenas valor utilitário. É também aquilo que confere poder a determinados grupos humanos ou pessoas em detrimento de outros. Partindo desses pressupostos antropocêntricos e etnocêntricos, o período histórico que corresponde ao desenvolvimento industrialtecnológico humano produziu um movimento crescente de aniquilação e apropriação das formas de vida animal em grande escala para o consumo humano. A produção industrial de animais, a manipulação genética e os testes de laboratório são as faces mais visíveis de um processo que estabelece uma série de questões éticas, estéticas e políticas incontornáveis atualmente ${ }^{7}$.

\footnotetext{
${ }^{7}$ No amplo campo que se abre na filosofia contemporânea sobre a ética e os direitos dos animais, critérios como a capacidade de sofrimento e a consciência da morte substituem a razão ou a linguagem na definição do que é um sujeito de direito. Os animais passam a ser pensados, nesse sentido, como sujeitos morais, com valor intrínseco e com o direito básico de não serem tratados como meio para os fins de outrem (SINGER, 1975; REAGAN, 1985; FRANCIONE, 2008).
} 
A discussão sobre as espécies que servem como alimento, as interdições alimentares e a relação entre alimento e ritual remete ao tema clássico da relação entre totem e tabu, tema que atravessa a psicanálise (FREUD, 1996), a antropologia e o pensamento estruturalista. A tradição antropológica tendeu sempre a apreender o animal em seus aspectos simbólicos e classificatórios. Desde a década de 1980, no entanto, uma série de estudos antropológicos tem se voltado para uma redefinição do simbolismo animal e da concepção de natureza. Essa temática possui múltiplos enfoques, sendo alguns exemplos as publicações organizadas de Descola e Pálsson (1996), Ingold (1994) e Milton (1993).

Assistimos, desde então, a uma multiplicação dos estudos antropológicos voltados para as relações entre humanos e animais, ou, em outras palavras, para os processos de formação de coletivos humanos-animais. Esses estudos incluem investigações etnográficas que abordam temas como a produção de animais para o consumo urbano, o universo das espécies de companhia, as redes de parentesco entre humanos e gado, a conservação de espécies ameaçadas, entre muitos outros. Em todos esses casos, os animais, em suas múltiplas interações com seres humanos, se apresentam como um desafio para o pensamento antropológico, levando a um esforço para se situar etnograficamente tanto a categoria do humano quanto a do animal (SEGATA et al. 2017; SEGATA e LEWGOY, 2016).

Nos regimes perspectivistas da Amazônia, por exemplo, animais e plantas são tratados muitas vezes como pessoas que têm sentimentos, desejos e pensamento análogos aos humanos; são, portanto, seres que conceberíamos como plenamente sociais, e não naturais (VIVEIROS DE CASTRO, 2002; DESCOLA, 2016). As relações entre xamanismo e caça no mundo indígena revelam um dispositivo relacional complexo envolvendo as figuras dos espíritos "mestres" ou "donos" dos animais e os xerimbabos, que são os animais domesticados. $O$ tema foi explorado por uma série de autores, entre eles Phillipe Erikson (2012), Eduardo Kohn (2007) e Carlos Fausto (2001). A conexão entre caça e sedução é também um tema tipicamente amazônico (TAYLOR, 1995; FAUSTO, 2001). Relações entre humanos e animais surgem nesse contexto como relações pessoa-pessoa, e não pessoa-coisa, como seria o caso na cosmologia ocidental.

Phillipe Descola observa a esse respeito que culturas tão diversas como os Araweté e Achuar da Amazônia, ou os Cree, da América do norte, orientadas, de acordo com ele, por sistemas animistas, jamais delimitaram suas fronteiras sociais dentro da espécie humana. Quando falam de animais 
e plantas, esses povos não estariam falando da mesma coisa que nós, herdeiros da tradição ocidental. De acordo com Descola, a expressão "seres da natureza" simplesmente não faria sentido nesse contexto (2016, p.13).

Por outro lado, e partindo de um enfoque diferente daquele da etnologia, os estudos de ciência e tecnologia têm fornecido abordagens novas e originais para as relações entre humanos e animais, baseadas no questionamento das práticas e saberes provenientes de experiências ocidentais. Um exemplo disso são os trabalhos de autoras como Donna Haraway (2005), que descreve a coevolução e a história conjunta de humanos e animais, e Vinciene Despret (2004), que formula a esse respeito o termo "antropozoogênese". Conceitos como o de "espécies companheiras" (HARAWAY, 2008) e de "etnografias multiespécies" (KIRKSEY; HELMREICH, 2010) surgem nesse contexto em como uma recusa dos preceitos antropocêntricos, buscando afirmar o modo como humanos e animais agem e são afetados reciprocamente em redes de relações.

A questão do animal ou a relação entre humanos e animais estabelece em todo caso um desafio que demanda novos modos de negociação e de discussão política, propiciando um debate amplo sobre os estatutos morais e epistemológicos que orientam o pensamento antropológico.

\section{Modos de conhecimento: ciência e saberes locais}

No decorrer da última década, filósofos da ciência como Bruno Latour e Isabelle Stengers se apropriaram do conceito de Gaia para refletir sobre as transformações ecológicas e a crise climática que assombra a nossa época (STENGERS, 2015; LATOUR 2017). Stengers usa o termo "intrusão de Gaia" para definir questões "cosmopolíticas" incontornáveis do novo milênio. Latour, por sua vez, se refere a um novo regime climático dentro do qual as atividades humanas e o mundo natural se articulam em conexões inesperadas. A teoria de Gaia foi formulada no campo das ciências da vida por James Lovelock, na década de 1960. Descrevia os sistemas complexos e frágeis de interações bioquímicas e termodinâmicas que se traduzem no fenômeno da vida terrestre (LOVELOCK, 2010). Tanto no caso de Latour como no de Stengers, guardadas as diferenças entre os autores ${ }^{8}$, a figura de

\footnotetext{
${ }^{8}$ A diferença entre as posições de Bruno Latour e Isabelle Stengers foi tematizada por Déborah Danowski e Eduardo Viveiros de Castro em Há mundo por vir? Ensaio sobre os medos e os fins (2014).
} 
Gaia evoca uma alternativa para os aspectos científicos, éticos e políticos articulados pelo conceito moderno de "natureza", cuja obsolescência se apresenta como uma questão incontornável atualmente.

A figura de Gaia traz o humano de volta para a Terra, para dentro das relações das quais nunca de fato se emancipou. Mas, esse retorno parece inevitavelmente marcado pelo sentido da catástrofe derivada da incompatibilidade entre o modelo e o mundo, o mapa e o território. A compreensão da inter-relação necessária entre o humano (a cultura) e a natureza também parece propiciar uma aproximação possível entre o pensamento científico contemporâneo e o pensamento de outros povos (não modernos) que de fato nunca conceberam o humano como um domínio separado e oposto àquele da natureza.

Procurei argumentar, até aqui, que as formas de conhecimento de povos indígenas e tradicionais são capazes de colocar em questão a forma como concebemos (seja na antropologia, seja nas ciências modernas) a oposição entre natureza e cultura. O contraste entre categorias científicas e categorias nativas remete ao célebre tema de Lévi-Strauss do pensamento selvagem (1962), que se produz a partir da inversão da importância dada às qualidades sensíveis, como cor, textura, cheiro, em oposição à ênfase nas qualidades ditas "primárias" com os quais o pensamento científico, ou "domesticado", trabalha. Essa relação entre conhecimento científico e saberes nativos remete de fato a um problema que atravessa toda a história da disciplina, que é o de repensar conceitos que foram naturalizados pela razão ocidental.

Desde Marcel Mauss e Malinowski, as economias de trocas regidas pelo dom, ou dádiva, permitiram à antropologia uma reflexão inovadora sobre o que seria a natureza da mercadoria e dos mercados. O pensamento de povos não ocidentais, de forma análoga, permitiu a Lévi-Strauss repensar os paradigmas de universalidade da razão e os fundamentos do pensamento científico. Os controles sociais da emergência do poder hierárquico e coercitivo, descritos por Pierre Clastres a partir das sociedades indígenas, produziram as bases de um questionamento amplo da lógica do Estado e das relações políticas.

Com inúmeros desdobramentos nas últimas décadas, por outro lado, os estudos de ciência e tecnologia forneceram modelos alternativos para pensarmos as práticas de conhecimento que não aqueles baseados na ideia proveniente da epistemologia clássica de que as ciências lidam com entidades frias e autônomas que pairam num mundo exterior ao 
nosso. Quando trata dos processos de modernização, como vimos, Latour argumenta que a ciência desempenha um papel crucial no relativismo, a partir da ideia de que é a concepção de uma natureza universal, mais do que qualquer outra coisa, aquilo que produz as bases para a expansão e a dominação promovida pelo Ocidente diante dos outros povos do mundo (2005, Op. cit.) As leis "universais" da ciência moderna, no entanto, têm uma história particular, e surgiram num determinado contexto (STENGERS, 2002). Neste caso, o questionamento da divisão entre natureza e cultura não parte do confronto com outras culturas, mas sim de uma reflexão ampla sobre as particularidades das práticas científicas.

Referindo-se às tensões e complementaridades entre os saberes tradicionais e científicos, Manuela Carneiro da Cunha mostra os equívocos que muitas vezes impossibilitam o diálogo intercultural. De um lado, a concepção da ciência moderna como um saber acabado e final sobre o mundo tende a desprezar tudo que aquilo que provém de protocolos alternativos. De outro, a ideia de que o saber tradicional é um patrimônio homogêneo e parado no tempo e não um processo dinâmico, tende a reduzilo ao campo das representações ou das crenças, neutralizando sua eficácia. A possibilidade do diálogo depende, nesse sentido, de um entendimento dos conceitos e métodos que não seja tributário da divisão entre fatos e valores característica do pensamento científico (CARNEIRO DA CUNHA, 2009).

Como observa Descola, a concepção de que o mundo é composto de humanos que se contrapõem a objetos naturais passivos faz parte de uma cosmologia particular; o problema é que tomamos essa cosmologia como algo universal (DESCOLA, 2016). Desta forma, nos tornamos, na maior parte das vezes, incapazes de ver algo além de uma história em que não há uma alteridade significativa. Precisamos muitas vezes ser lembrados, nesse sentido, de que os paradigmas da ciência derivam de um modo de conhecimento que se estabeleceu na Europa a partir do século XVII. Tratase de um movimento muito específico do pensamento, que produz uma determinada imagem do mundo, fundada nessa universalização daquilo que chamamos de natureza. Mas, o que a experiência antropológica mostra é que há outros mundos possíveis, outras naturezas possíveis. 


\section{Considerações Finais}

Em contraste com a ideia do multiculturalismo característico do relativismo cultural antropológico, Viveiros de Castro cunhou o termo "multinaturalismo" (2002; 2015). O conceito se referia originalmente ao mundo de perspectivas cruzadas das cosmologias indígenas, em que condições como a de humano, gente, animal ou planta de determinada espécie, ou espírito, não são substantivas e determinadas, mas antes transformacionais e definidas a parir das relações entre os seres. As consequências filosóficas, políticas e existenciais do multinaturalismo têm sido discutidas por seu autor desde que propôs o termo e estabeleceram diálogos e conexões com autores de diferentes campos de conhecimento.

$\mathrm{O}$ multinaturalismo articula-se com as discussões de Bruno Latour acerca da destituição da Natureza como território do Um, como substrato contínuo da existência, entidade transcendental e contínua em torno da qual orbitam culturas e sujeitos (LATOUR, 2005). A noção de cosmopolítica, formulada por Stengers (1997) questiona, em sentido semelhante, os paradigmas da natureza única a partir do entrelaçamento inescapável entre o ontológico e o político produzido pela diversidade de mundos disputados pelos coletivos humanos e não humanos em suas relações. A cosmopolítica dialoga com o multinaturalismo nesse sentido, o de pensar as relações político-metafísicas a partir da diferença, e não da identidade, assim como de uma recusa da homogeneização e da redução como procedimentos analíticos e descritivos. Não por acaso, a deriva dos autores citados, nos últimos anos, para a ecologia política e a questão da crise ambiental global tem em comum um questionamento amplo dos paradigmas "naturalistas" modernos. A evocação de Gaia, como visto, é significativa nesse sentido (DANOWSKI; VIVEIROS DE CASTRO, 2014, LATOUR, 2017, STENGERS, 2015).

A natureza como algo exterior e transcendente, apartada do humano, é enfim o que tornou possível o desenvolvimento das ciências, assim como a demarcação de uma separação absoluta entre o Ocidente e o resto do mundo. Essas duas grandes divisões fazem parte da concepção que origina um determinado tipo de história, fundada na ideia de progresso civilizatório e da emancipação do humano. O questionamento dos fundamentos que caracterizam o dualismo moderno parece, então, levar necessariamente a uma reflexão sobre os limites entre aquilo que se convenciona como sendo do âmbito da natureza ou do ambiente (e das ciências naturais) e aquilo que 
se convenciona como sendo do âmbito da sociedade ou da cultura (e das ciências humanas ou sociais).

Procurei argumentar que a oposição entre os domínios está fundada numa relação problemática entre a multiplicidade das culturas e a unidade na natureza. No pensamento antropológico, ou em disciplinas afins, penso que podemos encontrar sentidos alternativos, plurais e não essencialistas, que permitem vislumbrar alternativas às abordagens tradicionais desse dualismo, colocando em questão as relações entre observador e objeto de conhecimento, assim como as fronteiras entre humanos e não humanos.

\section{Referências}

AGAMBEN, Giorgio.

(2004 [2002]). The open - Man and Animal. California, Stanford University Press.

CARNEIRO DA CUNHA, Manuela.

(2009). Relações e dissenções entre saberes tradicionais e saber científico. In: Cultura com aspas e outros ensaios. São Paulo, Cosac Naify

CLASTRES, Pierre, (2003 [1974]). A sociedade contra o Estado. São Paulo, Cosac Naify.

CLIFFORD, James.

(2002). A Experiência Etnográfica. Rio de Janeiro, Ed. UFRJ.

DANOWSKI, Déborah; VIVEIROS DE CASTRO, Eduardo.

(2014). Há mundo por vir? Ensaio sobre os medos e os fins. Cultura e Barbárie.

DELEUZE, Gilles; GUATTARI, Félix.

(1997) [1980]. Devir-intenso, devir-animal, devir-imperceptível... . In: Mil platôs - Vol. 4. São Paulo, Editora 34. p. 11-115.

DERRIDA, Jacques.

(2002 [1999]). O animal que logo sou. São Paulo, UNESP.

DESCOLA, Phillipe.

(2016). Outras naturezas, outras culturas. São Paulo, Editora 34.
(2005). Par-delà Nature et Culture. Paris, Gallimard.

(1998). Estrutura ou sentimento: a relação com o animal na Amazônia. Mana, vol.4, n.1, p. 23-45.

DESCOLA, Ph.; PÁLSSON, Gísli (Orgs.).

(1996). Nature and Society. Anthropological perspectives. Londres, Routledge.

DESPRET, Vinciane.

(2004). The body we care for: figures of anthropo-zoo-genesis. Body and Society, vol 10 (2-3), p.111-134.

ERIKSON, Philippe.

(2012). Animais demais... os xerimbabos no espaço doméstico matis (Amazonas). Anuário Antropológico, II, p.15-32.

EVANS-PRITCHARD, Edward E.

(2005). Algumas reminiscências e reflexões sobre o trabalho de campo. In: Edward E. Evans- Pritchard; Bruxaria, Oráculos e magia entre os Azande. Rio de Janeiro: Jorge Zahar Ed.

FAUSTO, Carlos.

(2008). Donos demais: maestria e domínio na Amazônia. Mana, 14 (2), p.329-366. 
FRANCIONE, Gary L.

(2008). Animals as persons: essays on the abolition of animal exploitation. New York, Columbia University Press.

FREUD, SIGMUND.

(1996 [1913]). Totem e tabu. Edição standard brasileira das obras psicológicas completas de Sigmund Freud, vol. 13. Rio de Janeiro, Imago.

GEERTZ, Clifford.

(1982 [1973]). Interpretação das culturas. Rio de Janeiro, Ed. Guanabara.

INGOLD, Tim (Ed.).

(2000). Culture, Nature, environment. Step to an ecology of life. In: Tim Ingold (Ed.); The Perception of the Enviroment: essays on livelihood, dwelling and skill. London, Routledge. p. 13-26.

(1996). Kei debates in anthropology. London / New York, Routledge.

(1995). Humanidade e animalidade. Revista Brasileira de Ciências Sociais, n.28.

KIRKSEY, S. Eben; HELMREICH, Stefan. (2010). The Emergence of Multispecies Ethnography. Cultural Anthropology 25 (4), p.545-576.

$\mathrm{KOHN}$, Eduardo.

(2007). How dogs dream: Amazonian natures and the politics of transspecies. American Ethnologist, vol. 34 (1), p.3-24.

LATOUR, Bruno.

(2017). Facing Gaia. Eight Lectures on the New Climatic Regime. Polity Press.

(2005 [1991]). Jamais Fomos Modernos Ensaios de Antropologia Simétrica. São Paulo, Editora 34.

(2004 [1999]). Políticas da Natureza. Bauru, EDUSC.

LEACH, Edmund.

(1983) [1964]. Aspectos antropológicos da linguagem: categorias animais e insultos verbais. In: Roberto Da Matta; Edmund Leach: antropologia. São Paulo, Ática.

LÉVI-STRAUSS, Claude.

(1990) [1962]. O pensamento selvagem. Campinas, Papirus

(2013). Jean-Jacques Rousseau, fundador das ciências do homem. Antropologia estrutural dois. Tradução de Beatriz Perrone-Moisés. São Paulo, Cosac Naify. p. 45-55.

LOVELOCK, James.

(2010). Gaia: alerta final. Rio de Janeiro, Intrínseca.

MAUSS, Marcel.

(2003). Ensaio sobre a dádiva. In: Sociologia e Antropologia. São Paulo, Cosac \& Naify.

MILTON, Kay (Org.).

(1993). Environmentalism: The view from Anthropology. London, Routledge.

REGAN, Tom.

(1985). The case for animal rights. University of California Press.

SAHLINS, Marshall.

(2003) [1976]. Cultura e Razão Prática. Rio de Janeiro, Jorge Zahar Editor.

(1990). Ilhas de História. Rio de Janeiro, Jorge Zahar Editor.

SEGATA, Jean; LEWGOY, Bernardo; VELDEN, Felipe Vander; BEVILAQUA, Ciméa.

(2017). Apresentação. Horizontes Antropológicos, 23(48), p. 9-16.

SEGATA, Jean; LEWGOY, Bernardo.

(2016). Presentation. Vibrant, Virtual Braz. Anthr., v. 13, n. 2, p. 27-37.

SINGER, Peter.

(1975). Animal Liberation. New York, Harper Collins Publishers.

STENGERS, Isabelle. (2015). No tempo das catástrofes. São Paulo, Cosac Naify. 
(2010 [1997]). Cosmopolitics I. Minneapolis: University of Minnesota Press.

(2002 [1993]). A invenção das ciências modernas. São Paulo, Editora 34.

STRATHERN, Marilyn. (2014). 0 efeito etnográfico e outros ensaios. São Paulo, Cosac Naify.

TAYLOR, Anne-Christine. (1995). The Soul's Body and its States: An Amazonian Perspective on the Nature of Being Human. Journal of the Royal Anthropological Institute (N.S.), 2, p.201-215.

TYLOR, Edward. B.

(2005 [1871]). A ciência da cultura. In: Celso Castro (0rg.); Evolucionismo Cultural: Textos de Morgan, Tylor e Frazer. Rio de Janeiro, Zahar. p. 67-99.

VANDER VELDEN, Felipe Ferreira.

(2009). Sobre cães e índios: domesticidade, classificação zoológica e relação humanoanimal entre os Karitiana. Revista de Antropología. 25(1), p.124-144.
VIVEIROS DE CASTRO, Eduardo.

(2002). A Inconstância da alma selvagem. São Paulo, Cosac Naify. p. 345-400.

(2015). Metafísicas Canibais. São Paulo, Cosac Naify, N-1.

WAGNER, Roy.

(2010) [1975]. A invenção da cultura. São Paulo, Cosac Naify.

\section{Recebido em}

abril de 2016

\section{Aprovado em}

janeiro de 2018 